\title{
Immersion Training of Pre-Service Primary School English Teachers’ Professional Competence
}

\author{
Sun $\mathrm{Yu}^{1,}{ }^{*}$, Gao Tingting ${ }^{2}$ \\ ${ }^{1}$ School of Educational Science Harbin University, 150086, China \\ ${ }^{2}$ School of Educational Science Research of Heilongjiang University, 150080, China
}

Keywords: Pre-Service Primary School English Teachers; Teachers’ Professional Competence; Immersion Training

\begin{abstract}
With the continuous enhancement of China's comprehensive national strength and the increasing frequency of international exchanges, English learning is becoming more and more important. At the same time, the trend of English learning at a younger age is also widely concerned by the country, schools, parents and all sectors of society. Therefore, it is very important to cultivate the professional competence of pre-service primary school English teachers. This paper first defines the concept of teacher professional competence. Secondly, the necessity of immersion training of professional competence for pre-service primary school English teachers is expounded from three aspects, that is, professional consciousness, vocational ability and professional development. In the end, this paper focuses on the strategies of immersion training of professional competence for pre-service primary school English teachers, and gives some feasible suggestions to the readers.
\end{abstract}

\section{职前小学英语教师专业能力浸入式培养}

\section{孙宇 ${ }^{1 *}$ 高婷婷 ${ }^{2}$}

\section{1. 哈尔滨学院教育科学学院,哈尔滨市 150086; 2. 黑龙江大学教育科学研究院, 哈尔滨市 150080}

\author{
关键词：职前小学英语教师；教师专业能力；浸入式培养
}

摘要：随着我国综合国力不断增强, 国际交往日益频繁, 英语的学习变得越来越重要。同时, 英语学习的低龄化趋势也深受国家、学校、家长和社会各界的广泛关注。因此, 在职前阶段 培养小学英语教师专业能力是非常重要的。本文首先对教师专业能力的概念进行界定; 其次, 从专业意识、职业能力、专业发展三个方面阐述职前小学英语教师专业能力浸入式培养的必 要性; 最后重点论述职前小学英语教师专业能力浸入式培养的策略, 给与相关读者一些可行 性建议。

\section{1. 引言}

小学英语教师的专业能力是影响小学英语教育教学质量的重要因素。培养专业能力能够提 高小学英语教师的专业素质, 增强职业能力, 促进专业发展。因此, 培养职前小学英语教师 专业能力势在必行。

\section{2. 教师专业能力概念界定}

教师专业能力是随着实践的深入而逐步丰富的, 是专业意识、专业知识、教学实践等因素 相结合形成的综合能力, 其形成和发展的过程必须要经过教育教学实践的验证。只有在实践 中教师专业能力才会显得更有价值, 通过实践也可以不断检验教师专业能力发展情况。合格 的小学英语教师, 除了具备基本的思想素质和丰富的专业知识外, 还要掌握各种与教学工作 
相关的专业能力。所以，职前小学英语教师专业能力浸入式培养是非常必要的。

\section{3. 职前小学英语教师专业能力浸入式培养的必要性}

小学英语教师在职前培养阶段全程、全方位浸润在模拟或真实的教学情境中, 通过观察、 体验、感悟、反思、探究, 这种浸入式培养对于职前小学英语教师专业能力的形成和发展具 有重要意义, 能够促进教师专业能力不断的提升。

\section{1 职前小学英语教师专业能力浸入式培养是提高专业意识的需要}

“教师的专业意识，指的是教师在教育实践中意识到真正的问题及其背后的契机 ${ }^{[1]}$ ”。即教 师通过自主学习不断地完善教学理念和行为意识, 同时, 对自己的专业发展进行评估、总结 和规划, 并积极反思的能力。职前小学英语教师专业能力浸入式培养有利于加深教师对内心 世界和周围世界的认识, 提高自己对教师职业的自我认知和自身对职业的归属感。教师专业 能力提高也会对职前小学英语教师的专业意识起到引导、激励和监督的作用。

职前阶段对教师专业能力浸入式培养可以让职前小学英语教师按计划全程提升专业能力, 他们会自觉地、有意识地参与教学活动, 更好地在实践中开展教学工作。此外, 对职前小学 英语教师专业能力的浸入式培养, 会使他们有强烈的专业自觉意识, 始终对自己的专业发展 保持一种自觉状态, 在实践中确定自己的专业发展方向, 以实现最理想的专业发展。

\section{2 职前小学英语教师专业能力浸入式培养是增强职业能力的需要}

职业能力是人们在所从事职业的过程中, 形成的各种能力的综合, 即个人对所学知识、技 能在特定情境中整合后形成的运用能力, 即专业能力已经实践化、个人专业化了。教师专业 能力是教师职业能力的特征之一, 是教师在职业准备阶段获得的能力。对职前小学英语教师 专业能力的浸入式培养, 旨在增强小学英语教师职业能力, 也是检验教师素养的核心指标。

教师专业能力能够在教学中有效促进学生思维的发展、知识的掌握、情感的陶冶等。教师 职业能力的增强有利于促进学生的全面发展。职前教师专业能力的浸入式培养对学校整体发 展具有重要意义。“《国家中长期教育改革和发展规划纲要（2010～2020）》要求建设一支高 素质的师资队伍, 并将教师的专业能力作为教师发展的重中之重 ${ }^{[2]}$, 。教师是学校教育的主体, 提高其职业能力是国家教育事业发展的重要组成部分。

\section{3 职前小学英语教师专业能力浸入式培养是促进专业发展的需要}

“教师专业发展是教师专业能力不断更新、演进和丰富的过程 [3]”。教师专业发展是一种自 主发展的过程, 自主发展需要依靠能力和意识作为支撑。职前小学英语教师专业能力浸入式 培养能够坚定其专业意识, 不断发展和提升其专业能力。“教师终身专业发展是以职前教师专 业发展为基础的 [4]”。职前教师的职业定位对他们自己具有重要的意义。尽管职前教师没有进 入职业过程，但每一位职前教师都必须对教师工作的职责和地位等具有明确的认识。因此， 职前小学英语教师专业能力浸入式培养表明, 职前阶段的教学知识及相应能力的获得, 是教 师专业发展的重中之重, 也是教师成长的动力源泉之一。

\section{4. 职前小学英语教师专业能力浸入式培养的策略}

教师专业能力是在教师教育专业阶段培养形成的, 采用浸入式培养, 让职前小学英语教师 浸润到真实的教学情境中, 突出实际应用。在教学情境的再现中反思探究, 创新改进, 从而 实现职前与职后的无缝对接, 全程适用。

\section{1 与小学合作共建课程, 推行协同育人模式}

职前小学英语教师的培养需要一定的课程支持, 为使课程设置的更科学、合理, 小学英语 教师在职前培养阶段需要与小学合作共建课程体系, 推行协同育人模式。与小学英语教研员 
和小学一线骨干英语教师共建教法、技能训练类课程, 使职前小学英语教师与小学英语教育 教学密切联系, 理论与实践不脱节, 这种协同育人模式可以提高职前小学英语教师专业能力 培养的专业化和实践性。

职前小学英语教师通过共建课程可以倾听到一线小学英语教师的教学实况, 在听课中融入 教学情境中, 要认真看、仔细听、动脑想一线小学英语教师的每个教学流程, 进行反思和探 究。通过共建课程, 职前小学英语教师接受小学一线英语教师的课程培训, 培训的主要内容 是将英语教学理论和实践相结合, 并对教学方式、方法作细致讲解和独道分析,帮助职前小学 英语教师理解英语教学的宗旨。这些课程有利于职前小学英语教师在进入职场时, 更好地应 对所出现的问题。通过共建, 职前小学英语教师可以与小学英语教师进行经验交流。作为课 程的一部分, 经验丰富的小学英语教师会和职前小学英语教师分享自己的一些教学案例,通过 案例的展示会让他们在教学实践中更进一步地体会小学英语的教学理念和提高认知水平。这 样有助于职前小学英语教师教学经验的丰富及视野的开拓。

\section{2 采用全程实践模式, 在真实的情境中体验}

职前小学英语教师接受课程学习的同时, 也要在实践中不断发展自己的专业能力, 只有进 入在完全真实的情境中, 职前小学英语教师才会体验到教学的真正意义。因此, 职前小学英 语教师要采用全程实践模式，在真实情境中体验和发展。

职前小学英语教师进入小学进行教学实践。在真实的教学情境下, 职前小学英语教师将理 论自然地运用到实际日常中, 不仅锻炼了自身的英语思维能力, 而且也提高了英语交流能力。 职前小学英语教师也要参加学校组织的各种教学实践活动。实践活动的参与有利于提高职前 小学英语教师对教学理论和实践的理解与认识。在实践活动中,应创设大容量 “类似习得”的英 语语用环境, 通过英语知识墙、校园英语广播、英语节日等活动使职前小学英语教师于无形 中 “习得”英语。这一策略要求职前小学英语教师保持一定的英语输入量, 并在不同的情境和 活动中转换语言表达方式, 以增加职前小学英语教师语言输入的深度和丰富性, 还能够激发 职前小学英语教师的情感体验。总之, 教师专业能力浸入式培养模式下, 职前小学英语教师学 习到的理论知识, 还需要反复通过实践来检验。

\section{3 建立学习型团队, 促进专业知识增长}

在职前阶段有必要建立学习型团队，在交流和讨论中可以实现自己的学习和发展。学习型 团队结合了多个人的智慧, 把大家的想法汇集在一起, 通过提问、研讨、交流等一系列活动, 职前小学英语教师通过思想的碰撞, 不断地探索和创新教学, 专业知识和能力得以逐渐增长。 马克思指出, “一个人的发展取决于和他进行交往的其他一切人的发展 [5]”。职前小学英语教 师以学习型团队为依托在一起讨论各自的观点, 互相借鉴各自的的长处, 弥补自身的不足, 共同进步，达到双赢的良好效果，从而促进专业知识的增长和能力的提升。

学习型团队的建立, 要求职前小学英语教师要善于合作。实践表明, 积极合作的氛围对小 学英语教师的专业成长具有重要意义。对于职前小学英语教师来说,最初教学工作时,会面对很 大的压力, 语言、方法、策略都是他们经常面临的问题,在这种情况下,职前小学英语教师要积 极主动地与他人合作, 获得支持、指导, 并积极改进教学实践中的问题。在团队里,职前小学英 语教师的积极自我反思能力和自主发展意识能够很好地促进团队合作。

\section{4 开展反思与探究, 实现自我专业发展}

教师教学结束后会不断地反思自己的教学实践, 并从中发现自己的创新点和不足,积极地撰 写教学随笔、反思日记等, 以此来总结经验教训, 提高教育教学水平。职前小学英语教师也要 学会不断的反思和探究。在听课之后, 可以对教学实践再认识、再思考, 进行深层次学习。教 学实践后, 对于教师提出的教学建议进行整理和沟通交流, 将教学建议转化为自己的教学经验 和知识结构, 以此在不断反思和探究中快速成长, 实现自我专业发展。

职前小学英语教师自身的反思与探究非常重要。教师对教学实践的反思是教师成长的关键 
因素。在探究活动中, 职前小学英语教师专业能力的培养会使其专业发展得更快。他们能够 慢慢地参与到教学研讨活动中来, 并主动承担起教学科研任务, 为实现自我专业的发展增加更 多新的有效的教学理念。教学活动中的探究和反思为职前小学英语教师提供了“重新审视自己 教学实践、构建新的教学理念, 发展教学技能的机会, 是其认识教学、理解教学和学习教学 的重要手段, 有助于从根本上提高教育专业素养和实现专业成长 [6], 。教师自身的教学水平比 知识结构更重要, 其包含教师所具有的人格鬼力、积极的教学情感, 以此实现专业成长, 成为 一名有创新思维的、有前瞻性的、高素质的小学英语教师。

\section{5. 结 论}

职前小学英语教师专业能力采用浸入式培养, 让其全程坚持实践取向, 浸润在小学英语教 学的真实情境中, 使理论与实践能紧密结合, 达到学以致用。浸入式培养的最终目的是浸润 在教学情境中, 全面提升教师专业能力, 为成为一名合格的小学英语教师奠定夯实的基础。

\section{致谢}

基金项目：黑龙江省教育科学“十三五”重点项目：卓越小学教师培养的“浸入式学习”策略研 究与实践 (GBB1317059)

\section{[参考文献]}

[1] 何芳.论教师的自我专业意识及其专业发展[J].柊庄学院学报,2010,27(1):110-115.

[2] 徐蕴琦, 教师专业能力的影响因素及提升策略[J].辽宁教育行政学院学报,2016,33(4):31-34.

[3] 陈朝晖, 教学反思促进顶岗实习生职前教师专业发展的行动研究[J]. 湖北第二师范学院学 报,2011,28(11):108-111.

[4] 肖利, 赵敏, 刘慧, 刘茂军. PCK 视域下职前教师专业发展现状及对策研究 [J]. 教育探 索,2016(6):47-50.

[5] 马克思.马克思恩格斯全集第 8 卷.北京: 人民出版社，1961： 515.

[6] 白晓云. 基于教育体验的职前外语教师教学 反思能力培养 [J]. 中国成人教 育,2016,(3):141-143.

作者简介: 第一作者: 孙宇（1976-）, 女, 黑龙江省通河县人, 副教授, 硕士, 研究方向: 英语语言文学和外语教师教育

第二作者: 高婷婷（1995-）, 女, 黑龙江省大庆市杜尔伯特县人, 在读研究生, 研究方向: 教育经济与管理专业

*通讯作者: 孙宇 (1976-), 女, 黑龙江省通河县人, 副教授, 硕士, 研究方向: 英语语言 文学和外语教师教育。E-mail:1732412030@qq.com 